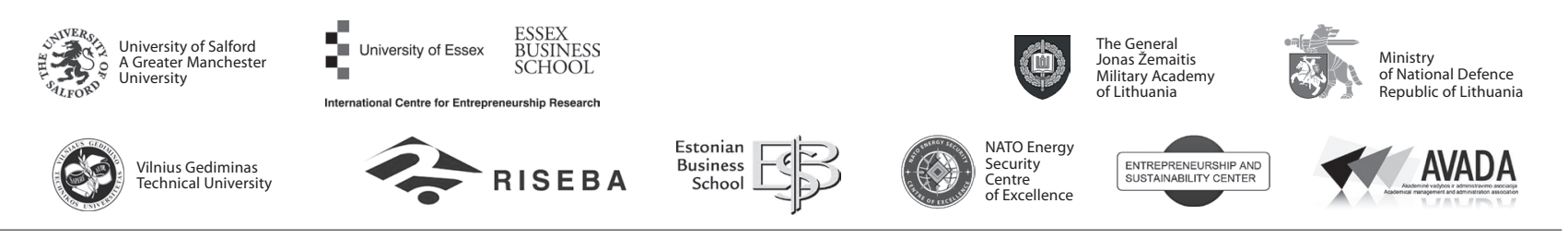

\author{
JOURNAL OF SECURITY AND SUSTAINABILITY ISSUES \\ ISSN 2029-7017 print/ISSN 2029-7025 online \\ 2017 September Volume 7 Number 1 \\ http://dx.doi.org/10.9770/jssi.2017.7.1(5)
}

\title{
PSYCHOLOGICAL ASPECTS OF OPERATIONAL AND INVESTIGATIVE ACTIVITIES AS A FACTOR OF STRENGTHENING OF THE NATIONAL SECURITY
}

\author{
Igors Trofimovs' ${ }^{1}$ Jānis Ivančiks ${ }^{2,3}$ \\ ${ }^{1}$ The State Police College of Latvia, Ezermalas Str. 8, Riga, LV-1014, Latvia \\ ${ }^{2}$ Daugavpils University, Parades Str. 1, Daugavpils, LV-5401, Latvia \\ ${ }^{3}$ Turiba University, Graudu Str. 68, Riga, LV-1058, Latvia \\ E-mails: ${ }^{1}$ dakpt@inbox.lv; ${ }^{2,3}$ janis.ivanciks@inbox.lv
}

Received 15 January 201; accepted 20 May 2017

\begin{abstract}
The authors deal with the history of formation of operational and investigative psychology as a field of knowledge influencing the national security. The article discloses in details some psychological essentials of the application of this knowledge in everyday activities of employees of special forces units, police, prosecutor's office, courts, punishment execution system and other law enforcement institutions. The authors also notes as important that during operational activities, in the process of determination of the truth, officers have not only to help in the reproduction of the facts, but also to try to achieve the truthfulness of the evidence. Because of applying, psychological techniques of operational investigative psychology create conditions for acquisition of correct and complete information about facts, particular events being of interest to law enforcement institutions ensuring necessary impact on persons who intentionally want to hide the truth and often forward false information. Therefore, the acquisition of psychological knowledge in the operational and investigative activities is a necessity for law enforcement institutions.
\end{abstract}

Keywords: national security, crimes, operational activity, psychological methods, truthful evidence.

Reference to this paper should be made as follows: Trofimovs, I.; Ivančiks, J. 2017. Psychological aspects of operational and investigative activities as a factor of strengthening of national security. Journal of Security and Sustainability Issues 7(1): 55-65. http://dx.doi.org/10.9770/jssi.2017.7.1(5)

JEL Classifications: K42, O10, P00

\section{Introduction}

Priorities of the state are guaranteening of national security, public order and state prosperity; prevention of civil disorders and crimes, protection of health and morality, as well as guarding of rights and freedoms. For implementation of this priority, each country has developed appropriate state authorities/ governmental institutions, which puts into effect above mentioned priorities, resp., executive institution and local governments have been established, that, in its turn, must ensure execution of certain instructions.

State authorities, which functions by law are ensuring of national security and lawfullness, protection of rights and legal interests of persons and the state, elimination of infringement of rights, application of state measures of constraint or public measures of influence to offenders of rights, are called law enforcement institutions (Zahars, Stivrenieks 2016). Each of these institutions operates within its competence sphere, and, cooperating between each other, forms a system of institutions which task is the protection of rights. 
The competence of the system of law enforcement institutions comprises prevention, detection and investigation of unlawful offences. A significant part of crimes are committed covert; criminals, especially organized criminal groups, act secretly, actively and purposefully against efforts of the state to detect and investigate their crimes (Tumalavičius et.al. 2016). Therefore, to clarify the truth, prevent and detect crime, it is necessary to execute operational activities.

Specific character of truth clarification in operational activities include the need to restore the facts, actions that may be determined only by the mediation of witnesses or participants of events/ incidents. In order of giving opportunity to witnesses to restore the objective reality as completely as possible, they always need a certain help. This assistance is doubtless nothing more than a certain psychological impact (Ratinov 1967). Most crimes are a twist of various very complex, mutually opposite interests of persons, by assistance of which the truth about the events and facts should be clarified in the process of operational activities. In the everyday life, the conflict of such interests leads to the situation that some individuals knowingly hide certain facts or intentionally deforms them.

\section{Objectives and tasks of operational and investigative psychology}

Each official of the subjects of operational activities (hereinafter referred to operational officer) bases inevitably during the work process on the data of psychology, sometimes without noticing it. This is empirical, everyday psychology, based on individual experience, knowledge of life and people.

However, along with empirical knowledge, an operational officer needs also scientific knowledge (Kavalieris, Makans 2008). However, this empiric knowledge, acquired finally by an experienced operational officer during long-time seeking and through disappointments, mistakes and discoveries, may be approved or, on the contrary, disproved in a very short time period and with sufficient accuracy thanks to objective psychological research.

Meantime, a detailed research of psychological basic principles in the Criminal Law, Forensics, Penitentiary Science and Theory of Operational Activities have lead to the development of such recommendations which allow to avoid many failures, make easier the work of operational officers, and, to some extent, compensate differences in their experience and skills (Sinilov 2016; Konovalova 1978). Therefore, knowledge of psychology is needed for both beginners and skilled operational officers.

The necessity to use results of psychological research in the field of operational activities is determined by the following specific features:

1. Operational activities have the character of constant and hidden conflicting interaction with criminal environment, with persons who plan, prepare crimes or who have already committed crimes. As a consequence, operational activities: are executed secretly related to a certain risk due to a lack of complete information about criminal events and persons involved in them, and, accordingly, depends on matter of chance to a certain extent; objectively contains possibility of failure of the carried out operational activities, and beginning of unwelcome consequences due to the counteractions of criminals; it is extremal because of constant diversity of organizational forms and tactical methods, regular shortage of time, availability of factors of professional risk and physical danger.

2. Operational activities are characterized by:

- constant analysis and forecasting of results of own activities and activities of criminal elements;

- constant operational readiness for actions in extreme situations.

3. Operational activities are:

- built on a regulatory and legal basis;

- related to involvement of diverse forces, means and methods;

- always conformed to the operational conditions and specific tactical situations;

- characterized by high dynamism due to a constant change of functioning environment. 
Of course, above mentioned specific features of operational activities are not full-scale ones, however, they are among the most significant. Even an incomplete list of these features shows with certainty that this activity, like any other, has significant psychological components, and the human psyche is its constant, necessary and highly dynamic element. In this regard, within the framework of Legal psychology and Theory of operational activities, the operational investigative psychology acquires its motivation. Regularities and mechanisms of psyche of individuals should be considered as subjects of operational investigative psychology. Individuals acts here as subjects of operational activities and as criminal elements opposing to them, namely, as persons engaged in illegal activities and their environment, as well as psychology of criminal groups and criminal communities, an also psychology of their conflictual interaction among themselves under appropriate objective conditions.

The aim of operational and investigative psychology is to add to the theory of operational activities the knowledge of logical and psychological regularities occurring in connection with the receipt of primary information about crimes in preparation or about committed crimes. These regularities find their expression in construction of versions and forecasts, and are related to the analysis of problematic situations in the circumstances of informational uncertainty and operational risk. They, resp., regularities are associated with the use of intuitive (unconscious) methods of operational thinking. At the present stage, the importance of social and psychological aspects of operational activities increases on its organizational and administrative level. It is about the use of data from psychological research when estimating and selecting personnel for operational units (professional selection).

Taking into consideration above mentioned, the main tasks of operational investigative psychology are formed:

- research of actual state of public relations of subjects of operational activities with citizens and criminal environment for objective assessment of dependency in the fight against crime and for development of sciencebased legal and psychological recommendations for improvement of them;

- promotion of professional and psychological development of individuality of subjects of operational activities in accordance with law enforcement functions carrying out by them;

- development of psychologically well-grounded recommendations for establishment of reliable relationship with people involved in the process of operational activities for prevention and detection of covert serious and very serious crimes, for solving of problematic and conflict situations arising from them, etc.

As we may see, the operational and investigative psychology similarly with the theory of operational activities according to their aims and tasks, is an applicable, practically oriented branch of the scientific knowledge.

\section{Methods of psychological influence/impact when receiving and transmitting information during communication.}

The practice of information receipt shows that psychological factors play a crucial role in this process. In most cases, the success depends on the ability of an operational officer to establish psychological contact with the interlocutor and influence his/ her psyche in the process of communication. Such influence is realized for different purposes (Ivančiks, Makans 1994). One of them is to provide certain information that the interlocutor would not like to share with anyone.

There are two main ways to obtain the necessary information:

1. To encourage the object to involuntary expression of facts that are of interest to operational officers.

For obtaining necessary information, the author identifies a number of the following methods:

Demonstration of specified articles/ things, which "animate" corresponding image in the memory of an object and encourage him/ her to involuntary expressions. For example, in order to find out whether a person of interest is familiar with religious articles, an offocer demonstrates unobtrusively any icons, crosses, bindings, which may objectively help to the relevant expressions, as well as to conversation in general. Moreover, for example, 
to find out some aspects of the life of the person of interest, you may use appropriate advertising materials, for example, to start a conversation about automobile theme - a newspaper, a magazine. The personal belongings of the object (telephone, toiletries, etc.), articles belonging to his/her relatives; other articles accessible to perception may also be used. The presence of such specific articles/ things gives a double psychological result. On the one hand, an album, for example, reproduces in the memory of the object images of the past stored there, and on the other hand - encourages to concrete expressions. It should be noted that the main rule of application of this method is the following: the encourage to involuntary expression when demonstrating objects reaches its specific aim only if an object does not realize that this article serves as a motive for expression.

Use of adjacent/ related topic of conversation. Such a topic enlivens a series of images in the memory of a person, inevitably capturing also images from the sphere of forbidden, respectively, only to him/ her known information into own mental outlook. Switching to a related topic may be realized through a variety of various neutral questions. The main conditions for the successful application of this method are as follows:

1) topic of conversation used as a related one must be known to the object and must have a certain personal significance and value for him/ her, the topic should not be too close to the main question to be found out, because otherwise, the topic acquires the character of a poorly camouflaged direct question;

2) a related topic should logically follow from the concrete situation. Therefore, the essence of use of adjacent/ related subjects of conversation for obtaining of information, being of interest to an operational officer, is: to revive impressions stored in the memory of the person of interest, to camouflage the actual meaning of the related topic and, as a result, to induce him/her to transmit unintentionally the relevant information.

Approaching to feelings of self-esteem. This technique involves praise, flattery, an emphatic expression of respect, great interest and attention related to the object. The technique is especially effective in dealing with selfish and ambitious people. Approaching to feeling of self-esteem makes possible to establish close relations with such people and promotes expression of sincerity from them. Conditions for successful application of this method:

1) before praise, one should always make a compliment; 2) when handling praise, one should take appropriate facial expression and pose; 3) to emphasize the "veneration" to/ "good qualities" of the object better when comparing him/ her with opponents. At the same time, one should know that everything is good in moderation, and this should not be forgotten.

Display of indifference. This technique is used when the interlocutor has a great desire to discuss the information that he/ she has at his/ her disposal, to mention in the conversation piece of news known only to and of great importance for him/ her. Expression of indifference to the information important from the point of view of the object and neglecting of it, hurts the self-esteem of the object, and thereby stimulates the presentation of additional data emphasizing the significance of this information. The conditions, which are necessary for successful application of this method, are as follows:

1) one have to feel in time that an object is "overflowed" with information. This is certainly noticeable in his/her behaviour: the object shoots frequent glances at he operational officer; she/ he cannot sit quietly in one place; the object begins to gesticulate intensely and shows that he/she possesses information;

2) it is not allowed at this time to expose to the object your topic of conversation; 3) expression of indifference on the side of an officer may induce the object to speak only under conditions of trust.

Use of emotional stress. The condition of psychic strain is understood under emotional stress in this case. In this condition, a person's control over his/ her behaviour and expressions is weakened. There are several stages in the development of this condition. The main stage is a period of intensive emotional experiences, poorly controlled actions and speech reactions. As a result, the emotional stress comes at an end with a gradual transition to peacefulness. You can put the object into a state of emotional stress by asking an unexpected question; by making an inaccurate or false statement by reporting seemingly "important" information; or by showing your competence in anything. 
Furnishing offalse evidence. It is known long before that a person has trust in ideas that arise in his own head much more than in those, which are presented to him/ her by other people. Therefore, professionally experienced operational officers try to avoid direct pressure on the object as much as possible, and prefer indirect influence on the way of thinking of the object. To do this, officers, as it were, inadvertently toss to the object certain information, the conclusions from which the object must do oneself. The art of obtaining information is based exactly on the fact that due to the competent submission of certain facts, the object of our interest has to draw precisely those unambiguous conclusions and deliver it to a listener, as an operational officer had intended.

Creating an image of "simpleton". The essence of this method is that an officer, intentionally belittling his own mental abilities, tries to create the feeling of intellectual superiority in an object. As a result, the object loses alertness, as it does not expect any intrigue from this "simpleton" with which he/she communicates. In fact, a simpleton proves to be the object.

The second way to obtain necessary information is:

2. To encourage the object to involuntary physical and expressive activities, containing corresponding information.

The methods, using which this technique of obtaining information is realized, are the following: Demonstration of concrete articles/ things related to criminal activities of an object.

This method is successfully used in operational and investigative practice. As an example, we may give some facts about the expressive reactions of the detainee C. to articles/things related to his criminal activities. In the process of inspecting the place where he left his car, bank pouch with money, he had stolen and had hidden being in hiding from the police tracking, was confiscated. In order to verify the psychological impact of confiscated bank bags on S., the officer, as it were, accidentally opened the safe door at the beginning of one of the examination, in which bank pouches were placed. Seeing the bank bags, he behaved nervously during the entire interrogation, and in the prison cell concretely stated: "Everything is lost. They have found money ...". Continuing to apply the planned tactical techniques, the employee left on the table a bank pouch similar to the one stolen by the detainee. The detainee watched the pouch for a long time, and during signing the minutes, he touched the pouch convulsively. In this case, the object reacted to stimulating influence resp., thing with expressive or physical actions. He, of course, was quite aware of the significance of such articles/ things, but his expressive movements (in facial expressions, posture, fingering) were completely unconscious. However, exactly these involuntary reactions contain the information being of interest for investigation officers, that is, information about involvement of a person in committed crime. Provisions of practical use of this method are as follows:

1) specific articles/ things to be demonstrated must be truly or eventually related to the criminal activity of this subject;

2) the subject must perceive these things in a corresponding situations;

3) actions and behaviours of a person who demonstrates the article/ thing must express his/ her neutral relation to these thing, and must be adequately motivated.

Creation of short-term psychologically sharp life situations. Such situations may be either naturally developed or artificially created. Therefore, this technique was applied enough successfully during search a place of a drug dealer. While the search was executed in the rooms, the drug dealer showed no signs of worry, indifferently staring out the window. After a while, one of the officers went into the kitchen and suddenly gave a cray: "Here is!" The drug dealer suddenly gave a jump, ran into the kitchen and looked at a locker above the refrigerator. In the created unexpected and psychologically sharp situation, wanting to make sure that the hiding-place is found, the drug dealer involuntarily gave his view to the place where the hiding-place with a large amount of drugs really was. During the other search a place, another similar situation occurred. When searching a room, 
at the beginning of the search of a corner cupboard by a policeman, the owner, who behaved quite at ease and even superficially, suddenly fell silent and became gloomy. This alerted the police officers and forced them to move the wardrobe: as a result of which the stolen goods were discovered in the room of the owner, masterly hidden behind a false wall.

The conditions for successful application of this method are:

1) situations to be created must have personal significance for the subject;

2) it is important to choose such a moment for creation of a situation that the subject have to react mandatory to it;

3) actions of the person who uses the situation should follow logically from this situation and should receive appropriate expressive confirmation;

4) mental/ psychological conditions and expressive motions of the object must be thoroughly fixed in response to the created situation.

These motions are subconscious, so the degree of reliability of condition of the subject and his intention reflected in these motions is sufficiently high.

Thus, psychological methods and techniques of obtaining of interested information, outlined in these methods, are based on the general regularities, of unconscious mental phenomena that appear outwardly as unintentional voice reproduction of information, as well as expressive and physical actions of the subject.

One of the aims of the operational activity - influence/impact on persons who have committed a crime, impact on unstable individuals who probably may commit a crime - is achieved by various methods, including also the methods of psychological influence. Specific feature of establishing the truth during execution of operational activities is the necessity to restore the facts or actions which identification in many cases is possible only through evidence of persons who were witnesses or participants. In order to enable reproduction of objectively existing facts as much as possible by witnesses, it is always necessary to provide some assistance to them. This aid, no doubts, may not be anything else that a certain psychological impact. In most cases, events of a crime are a very intricate interweaving of diverse, sometimes even conflicting interests of those persons through whom in the course of operational activities we have to establish the truth about the events and facts. In reality, these contradictions of interests make sometimes situation that some people do not report information deliberately, known to them or purposely distort them. Therefore, during operational activities, in the process of establishing the truth, we have not only to help in reproduction of facts, but also to ensure the reliability of evidence. In this situation, psychological methods of influence create the conditions for obtaining from all persons, which are listed in available materials of the case, correct and complete information about facts, concrete events being of interest for law enforcement institutions which provide necessary impact on persons who intentionally want to hide the truth from the inquiry and investigation, and often deliver false information.

It should be noted that there are a number of principles, without preliminary taking into account of which, the purposes of impact in the course of operational activities may not be achieved:

1. The impact should be carried out taking into account specific characteristics of individuality. Among these specific characteristics of individuality, first of all, the type of temperament and mental condition of individuality at concrete time should be taken into consideration.

2. The process of carrying out the impact requires knowledge of the general regularities of familiarization of information by an individual, of specific of its perception in the communication process, of factors influencing activation of the process of information acquiring onto the thinking process, of the influence of emotional processes onto the mental activities, onto the performed impact.

3. The impact process, its elements, counter-action of a person, on which the impact should be planned and predicted in advance. 
4. The positive perception of the impact must be stimulated obligatory. This is achieved in various ways: an indication on achieved results, verbal encouragement, etc.

5. The impact must be strictly limited to procedural competences in all cases, in no case the rights of the impacted person should be violated.

6. When executing impact, it is necessary to take into account external conditions in which the impact is carried out. External conditions should help to achieve impact aims. In all cases, one needs to know, to foresee conditions that may ensure effective application of psychological methods of impact/ influence.

7. When executing impact, it is necessary to provide mental activity of a person to which the impact is directed. The impact will be effective only in the case, if it is actively ensured and perceived. At the initial stage of the impact process, some interest in the conversation should be awaken.

8. The impact during implementation of operational activities should be carefully prepared. So, before executing the impact, the initial data should be taken into account, namely, the data that include information about a person, its behaviour, condition immediately before the impact; determination of final and intermediate aims of the impact; sequence in achieving intermediate aims; facts and circumstances that are possible to use; sequence of such use; information about impact from the side of other persons.

The main methods of psychological impact are as follows - method of delivery of information, method of persuasion, method of compulsion, method of implantation/ suggestion, method of setting and varying of mental/ thinking tasks.

Method of delivery of information. Under this method the purposeful transfer of facts, events, knowledge is to be understood. Under the circumstances of operational activities, the method of delivery of information helps to make certain changes and directions in mental processes of a person to whom the impact is applied. The essence of the method lies in the quality that the information gathered previously and transmitted in accordance with a certain order, conditions and technique, includes a person to whom the impact is applied in intellectual, emotional, volitional processes, then is processed by him/ her and leads to the achievement of the anticipated aim of the impact. This method is used for a variety of aims: to assist in memorizing of the forgotten, to change the direction of thinking processes of a person, which gives false evidence; to change settings, views, world outlook; to initiate certain emotional condition.

Information may be perceived by different organs of sense (eyesight, hearing) separately or simultaneously. Information designed for visual perception, in its turn, may be presented to the subject differently. In some cases, it is possible a direct addressing of the attention on a certain object ("look at the icon"), in other cases - to create conditions that provide a visual perception of an object without such addressing, as it were accidentally. Such information may affect the thinking processes and guide them no less strongly. Information may be transferred in the speech in any grammatical form: interrogative, affirmative and negative. The form of delivery of information differently stimulates the processes of mental activity, and may be used in different ways for such impact. During application of various forms of delivery of information, the condition of a person at the time of communication should be taken into consideration. It is also necessary to monitor constantly the impact of information. To do this, it is important to make sure that a person has understood what was said to him/ her, to observe carefully his/her reaction and verbal expression. All of these factors should be considered when planning the impact using this method.

The method of delivery of information may be applied for restoring of information forgotten in the memory. In order to obtain more objective results, it is advisable that the additionally transmitted information would more fully restore that information, which to a person seems that he/ she remember it, and does not directly prompts the replay to a question asked.

The method of delivery of information is widely used also for the change of person's attitude to his/ her behaviour and to the facts delivered by him/ her. The impact by using information is capable to change the volitional decisions of a person, helps him/ her to revise previously chosen course of behaviour. In this regard, this 
method must be widely used in operational activities, resp., in situations when enquired or suspected person reports false facts or hides them.

Method of delivery of information is used in cases when it is necessary to change sharply the emotional state of a certain person. The delivery of additional information may be used to remove the brake action (excitation) by sharp excitation of new strong emotions or by gradually switching of the attention of interested person from the facts, on which his/her thinking activity was concentrated, to other facts.

Method of persuasion. The persuasion - this is the main method of impact/ influence. The following is understandable under this method: on the one hand, the diverse influence on the individual with the aim to form certain qualities and to get rid of others ones, and on the other hand - the urge for certain activities. This method is widely used in operational activities. The main components of the persuasion are: providing of information (narration), explanation, proving/argumentation and disproof, as well as the talk.

An important role in urging of a person to activity plays information, which is necessary, because a person before to do something must be convinced that it is necessary and possible to do. Informing appears as a story/ narration, i.e. lively and pictorial explanation of information with the aim to inform the object about facts and findings which are necessary to induce his/her for working. Being free in its form from any canons, the narration/story allows an officer to use in full all of his/her skills to convince and persuade the interlocutor. Telling something to the explored person, the inductive way may be chosen, that is to inspect step by step facts, phenomena, occurrences and then to make generalizations; or - the deductive way may be chosen, that is, first of all to draw general conclusions and then to bring the facts for supporting the conclusion.

The process of persuasion should always help a person to make the right decision, to identify faults and to acknowledge own guilt. The persuasion is in all cases the process comprising always the following basic elements:

1) explanation of certain arguments;

2) delivery of information confirming correctness of stated arguments;

3) hearing of doubts and objections of the person to be persuaded;

4) explanation of new arguments taking into account objections;

5) repeating of certain arguments and elements of delivered information with the aim to make more perfect impact onto mental processes of the person to be persuaded.

When implementing the persuasion, the following should be taken into account: all the positive features and qualities of the person to be persuaded; appropriate accentuation of the attention on them, using also the opposition to their characteristics and settings of other objects. It is very important to identify the points of hesitation, doubt of the person to be persuaded. In this regard, in the process of applying of the method of persuasion, the careful examination of personality; observation of his/her reactions, changes in behaviour, facial expressions, gestures, and so on, should be continued.

A prerequisite condition of use of persuasion methods is establishing of psychological contact, which usually is characterized by positive attitude to the person who makes persuasion, as well as by desire to perceive his her arguments.

Method of compulsion/ coercion. It is known that it is not always possible to achieve success by influencing a person with persuasion. Sometimes, it is necessary to use also compulsion/ pressure. However, it should be noted that "naked" compulsion, insulated from the persuasion, is destructive in many cases. It is important that the object of influence, to some extent, would be conscious of inevitability of coercive measures taken to him. This is possible to achieve, as a rule, in the case when the compulsion is preceded by persuasion. 
By its nature, compulsion is divided into physical one (is not examined) and psychological one. Psychological compulsion acts as an encouragement of interested person to a particular activity, unlike to his/ her wishes. In the process of psychological compulsion, the object executes an order in the condition of a strong internal protest. Only external circumstances force him to obey. Therefore, an essential condition for the use of the method of compulsion is an external precondition. If such precondition is absent, the compulsion becomes senseless. In the circumstances of operational activities, the feeling of fear acts as a precondition for compulsion, which in its primitive form is associated with the unconditioned defensive reflex and most elementary is manifested in the mechanisms of self-preservation. It is known, that the fear is caused and becomes stronger, when a person is aware of and sometimes suffer sharply from his/ her vulnerability and weakness. The officer has to know this regularity and has to understand clearly that the fear has little effect on a strong person. For an unstable person, the fear is a very strong stimulating factor. This means that the compulsion is related not only to external factors, but also, of course, to internal, psychological ones. As a rule, the fear arises mainly because of the verbal impact.

It should be noted that when assessing the possibility of using compulsion to a certain person, you have mentally to take his/ her point of view and draw conclusions whether the feeling of fear arises in this person, for example, after the presentation of compromising materials to him/ her. If a person, after understanding of situation, will evaluate it for him/ herself as dangerous, he/ she will be encircled by fear to some extent. The use of compulsion is justified in this case. However, if the object did not see danger in this situation, and fear does not arise, the use of compulsion will be senseless.

The basic techniques of psychological compulsion during activities of operational officers are prohibition, categorical demand, warning and menace/ threat.

Prohibition acts in two ways:

a) the prohibition of impulsive actions;

b) the prohibition of unpermitted behaviour.

Categorical demand includes a strong command/ order and may be effective only if an officer has a great authority/ influence on the object. In other cases, this technique may be useless and sometimes even destructive.

Warning, The sense of warning is that an officer provokes in the object anxiety/ alarm, and, respectively, on it base - the desire to prevent negative consequences for the object. The tone is very important part of the warning, in addition to the content. It should be impressive, with elements of threat. All this makes an obvious pressure on the object and causes in his/ her mind mostly negative feelings; and predominance of anxiety and fear regarding the consequences of their behaviour arises. This is what motivates the object to comply with the requirements of an officer.

Menace/ threat crowns the hierarchy of psychological compulsion, bringing the object to the strongest emotional experience, creates feeling of fear. In order to apply the anxiety, it is necessary that it should cause feeling of fear to the object. Some people are very resistant to feeling of fear. Therefore, it is quite difficult to apply compulsion to them. In order to influence such persons psychologically, the method of suggestion is applied.

Method of implantation/ suggestion - one of the means of mutual influence of people in the process of their communication. The specific of implantation is expressed in the fact that it affects the behaviour of the influenced object invisible for him/ her. Uncontrollably penetrated into psyche, implanted idea is realized in the form of actions. However, the person evaluates his/ her actions as self-evident.

Operational activities, saturated by various elements of communication, are a wide sphere for implantation. Hence it is clear that the mastery at least of a part of implantation methods is very important for an operational officer. The implantation, as a method of influence onto a person, is a psychological impact perceived by an object without proper control of consciousness. The suggesting influence is based on the specific quality of 
the human psyche - suggestibility, i.e. the ability to perceive the implantation/ suggestion. In order to use the methods of implantation, we must be able to identify suggestible people. The degree of suggestibility depends mainly on the nature of the social role of an individual, an abrupt change of which, as a rule, creates favourable conditions for increase of suggestibility. And on the contrary, increase of the importance of the executed social role leads to the increase of independence of an object, based on a critical attitude to own actions. However, a number of circumstances should be taken into consideration. In particular, the older is the person, the harder he/ she is influenced. The reduction of suggestibility occurs gradually, in the course of education, social interaction and practical activities of individuals. Educated people are less suggestible than uneducated. Suggestibility depends also upon the level of cultural development of the nation. It should be noted that women are generally more suggestible than men. However, if a woman takes a long time prestigious position in society or if she acts as a leader, her level of suggestibility may be lower than that of a man.

To ensure the implantation/ suggestion, it is necessary to "place" the person, which will be implanted, into a specific background condition in which he/she would be "deaf" to everything except the information of a person performing implantation. The most simple, but at the same time also the most reliable method of adoption of the person, to be implanted, into a background condition, is relaxation of this person; and about effectiveness of relaxation may be judged according to a number of indications: body lean back on the backboard of a chair, blushful face, bright eyes, freely straddled legs, straightened out hands, etc.. Figure bent down over the table, bent legs, wandering eyes, wrinkles on the forehead and vertical folds on bridge of the nose point to the stress condition of the object.

Method of setting and varying of mental/ thinking tasks. The impact/influence is carried out not only by delivery of certain positive information. The informational impact may occur in the form of the question - mental/ thinking task. Its main essence is setting of tasks with the aim of development, direction of thinking processes of persons to whom the impact is executed. The impact is executed:

1) by techniques of setting task (question);

2) by orientation of thought processes as a result of formulation of a task (question);

3) by assistance in solving of thinking problem.

By assistance of setting mental tasks, the process of analysing of own actions and behaviour is stimulated. This is an indispensable condition for acceptance of certain decisions of will, for changes of attitude to own behaviour and actions. This may not be achieved only by delivery of information or solely by persuasion. It is necessary that active processing of all facts, all delivered arguments, would be made by a person, who is influenced. The method of setting mental/ thinking tasks fulfils exactly this role.

This method is widely used in operational activities also when uncovering false evidence. The fact is that a person who knowingly gives false evidence has two mental models of the event, about which the evidence is given. One model represents an event in the form as it was in reality, and the other model - delivered version of the event. The presence of these two models leads to complication of mental filtrations after setting a mental task - a question. The person who gives false evidence seeks to combine these two models in details as much as possible- only in such a case the false version will be believable. In condition of such complicated mental work, using efficient formulation of questions, varying them, by unexpected formulation of questions, by hiding the main question with series of small, insignificant questions - the situation appears, when a person, who is influenced by this method, does not manage to control the relevance of the question to the model of the true events and reports facts related exactly to this and not to the fictional event. 


\section{Conclusions}

The knowledge of psychology is highly important in clarifying the truth. In order to find out the truth, to draw the appropriate conclusions, one has to know and follow the laws of psychology. In addition, the knowledge of psychology makes possible to control own cognitive, volitional, emotional processes, to check and direct these processes of other persons, to take right decisions.

The main task of activities of employees of operational units of law enforcement institutions is working with people. This work includes a number of interrelated aspects: research and evaluation of people, establishment and development of psychological contacts with them, making impact on them, etc.

The knowledge of psychological characteristics of offenders and of reasons of committed crimes is of great importance for improvement of operational and investigative activities and for investigation of crimes, as well as for improvement of their effectiveness.

The purpose of operational and investigative psychology is to add to the theory of operational activity the knowledge of logical and psychological regularities occurring in connection with receipt of primary information about prepared or committed crimes. This knowledge finds its expression in construction of versions and forecasts and is related also to the analysis of problematic situations in the conditions of informational uncertainty and operational risk.

Acquisition of psychological knowledge in the operational and investigative activities is the must for law enforcement institutions. However unfortunately, there is no specialized course - psychology of operational activities in Latvia at present time. This significantly reduces the efficiency of operational and investigative activities. The authors see the necessity of introducing the course of psychology of operational activities in specialized educational institutions.

\section{References}

Ivančiks, J.; Makans L. 1994. Agency work. Riga: Latvian Police Academy, 94.

Kavalieris, A.; Makans L. 2008. Introduction to Criminal Investigation. Riga: Latvian Police Academy, 24-46.

Konovalova, V.E. 1978. Psychology in the investigation of crimes: Har'kov: Vysshaja shkola, 18-56.

Ratinov, A.R. 1967. Forensic psychology for investigators: Moskva: Vysshaja shkola MOOP SSSR, 5-11.

Sinilov, G.K. 2016. Introduction to operational-search psychology: Moskva: Norma: INFRA-M, 16-36.

Teivans-Treinovskis, J.; Lavrinenko, O. 2016. Assessment of Social Factors and Conditions Of Deviant Behavior In The Modern Society. Criminology Journal of Baikal National University of Economics and Law, 2016, vol. 10, no. 1, pp. 73-81.

The amendments of the Operational Activities Law.. 2016. LV, 57 (5629), 22.03.2016./Stājas spēkā 01.08.2016. Available in Internet: $<$ http://likumi.lv/ta/id/281095-grozijumi-operativas-darbibas-likuma>.

The Law on Operational Intelligence Activities. 2016. Available in Internet: <http://orka.sejm.gov.pl/proc6.nsf/projekty/353_p.htm>.

The Operational Activities Law. 1993. /Pieņemts Latvijas Republikas Saeimā 16.12.1993.; stājies spēkā 13.01.1994.; ar grozījumiem, kas pieņemti līdz ar 04.04.2012.

Tumalavičius, V.; Ivančiks, J.; Karpishchenko, O. 2016. Issues of Society Security: Public Safety under Globalisation Conditions in Lithuania. Journal of Security and Sustainability Issues, 5(4): 169-570. DOI: http://dx.doi.org/10.9770/jssi.2016.5.4(9).

Zahars, V.; Stivrenieks, M. 2016. Security and Safety Enforcment: Execution Peculiarities. Journal of Security and Sustainability Issues, 6(1): 72-77. DOI: http://dx.doi.org/10.9770/jssi.2016.6.1(12). 